\section{Auditory differential conditioning of the rabbit nictitating membrane response: II. Effects of interstimulus interval and cue similarity'}

DRAKE C. CHISHOLM, RALPH B. HUPKA, and JOHN W. MOORE, University of Massachusetts, Amherst, Mass. 01002

In Experiment 1 each of 48 Ss was given 3 days of conditioning in a 3 by 2 factorial design combining interstimulus intervals (ISIs) of 250, 500, and $1000 \mathrm{msec}$ with frequency separations $(\Delta f)$ between the reinforced $(C S+)$ and nonreinforced $(C S-)$ conditioned stimulus of 200 and $1400 \mathrm{~Hz}$. The results revealed poor differentiation with $\Delta f=200 \mathrm{~Hz}$ and uniformly good differentiation with $\Delta f=1400 \mathrm{~Hz}$. This finding suggests that the effect of ISI upon differentiation is minor. The purpose of Experiment 2 was to determine whether the inhibitory influence of nonreinforcement was greater in a partial reinforcement paradigm, where the same CS is as often reinforced as nonreinforced, than in a differential conditioning paradigm with discriminably different CSs. A comparison of rate of responding to $C S+$ between a group of eight Ss given $50 \%$ partial reinforcement with two groups of eight $S s$ receiving differential conditioning at two levels of $\Delta f(600$ or $1200 \mathrm{~Hz})$ indicated that the partial reinforcement $S s$ did not differ significantly from the two differential groups.

The purpose of this experiment was to examine the relationship between differential conditioning and interstimulus interval (ISI). On the basis of Hartman \& Grant's (1962) experiment in human eyelid conditioning, it was expected that an ISI greater than $250 \mathrm{msec}$, thought to be optimal for simple conditioning (cf. Schneiderman \& Gormezano, 1964), should yield better differential conditioning. Hartman and Grant varied ISI between 400 and $1000 \mathrm{msec}$ and found 800 to be optimal for differentiation. This value seemed to provide the best balance between an excitatory process which grows most effectively at a relatively short ISI and an inhibitory process which is optimized at a relatively long ISI. A decision-making factor might also have been indicated in the sense that Ss could use the longer ISI to categorize the $\mathrm{CS}$ as plus or minus and modify the likelihood of a CR accordingly. While the present experiment cannot definitely distinguish between these alternatives, it would seem parsimonious to minimize the impor- tance of such a cue recognition and decision-making process in the event of a close parallel between the human and rabbit data.

\section{EXPERIMENT 1 \\ Subjects}

The Ss were 48 naive male and female New Zealand White rabbits, 90-120 days old.

\section{Apparatus}

A detailed description of the apparatus and technique for recording from the nictitating membrane has been provided in a previous report (O’Malley, Hupka,\& Moore, 1969).

\section{Procedure}

Interstimulus intervals of 250,500 , and $100 \mathrm{msec}$ were crossed in a factorial design with tonal separations between CSt and $\mathrm{CS}-(\Delta \mathrm{f})$ of 200 and $1400 \mathrm{~Hz}$. The tones employed were 900 and $1100 \mathrm{~Hz}$ for $\Delta \mathrm{f}=200$, and 300 and $1700 \mathrm{~Hz}$ for $\Delta \mathrm{f}=1400$ (counterbalanced). A conditioned response (CR) was defined as any $1-\mathrm{mm}$ positive deflection of the recording pen within the interstimulus interval. The UCS consisted of a $2-\mathrm{mA}$ ac shock of 50-msec duration applied to wound-clip electrodes on the infra-orbital region of the right eye. Eight Ss were run in each of the six principal groups for 3 days. In view of the finding that rate of differentiation is between CS+ and CS-. facilitated when separate-phase conditioning precedes mixed-phase conditioning (O’Malley, Hupka, \& Moore, 1969), Ss were given $60 \mathrm{CS}+, 10 \mathrm{CS}-, 20 \mathrm{CS}+, 10 \mathrm{CS}-$, and 20 differential trials (i.e., CS+ and CS-- were presented equally often in a random sequence) on Day 1. Days 2 and 3 consisted of 120 differential conditioning trials per day.

\section{Results and Discussion}

Plotted in Fig. 1 are mean percentage of CRs to $\mathrm{CS}+2$ for the first six blocks of Day 1 (ACQ) and mean per cent CRs to CSt and CS- , averaged over Days 2 and 3. Figure 1 shows that differentiation over Days 2 and 3 for $\Delta f=1400$ was best with an ISI of $500 \mathrm{msec}$, somewhat poorer at $1000 \mathrm{msec}$, and poorest at $250 \mathrm{msec}$. While these results are consistent with Vandercar \& Schneiderman's (1967) findings that an ISI of $750 \mathrm{msec}$ was optimal for differentiation in a comparison of ISIs of $.25, .75,2.25$, and $6.75 \mathrm{sec}$, the fact remains that the level of differentiation at $\Delta f=1400$ in the present study was uniformly good, and there was no statistically significant difference between ISIs. Furthermore, in agreement with Schneiderman \& Gormezano (1964), Fig. 1 shows that the initial acquisition rate (ACQ) was clearly better with an ISI of 250 than with the longer ISIs $(\mathrm{F}=5.28, \mathrm{df}=2 / 36$, $\mathrm{p}<.01)$. Thus, this experiment suggests that while ISI is a critical parameter for acquisition, its effect on differentiation may be slight. This being the case, the parallel between the rabbit and human $S$ s in the Hartman \& Grant (1962) study was not so close as to diminish the possible importance of the cue recognition and decision-making factor in their study.

Differentiation at $\Delta f=200$ was uniformly poor, but the fact that some

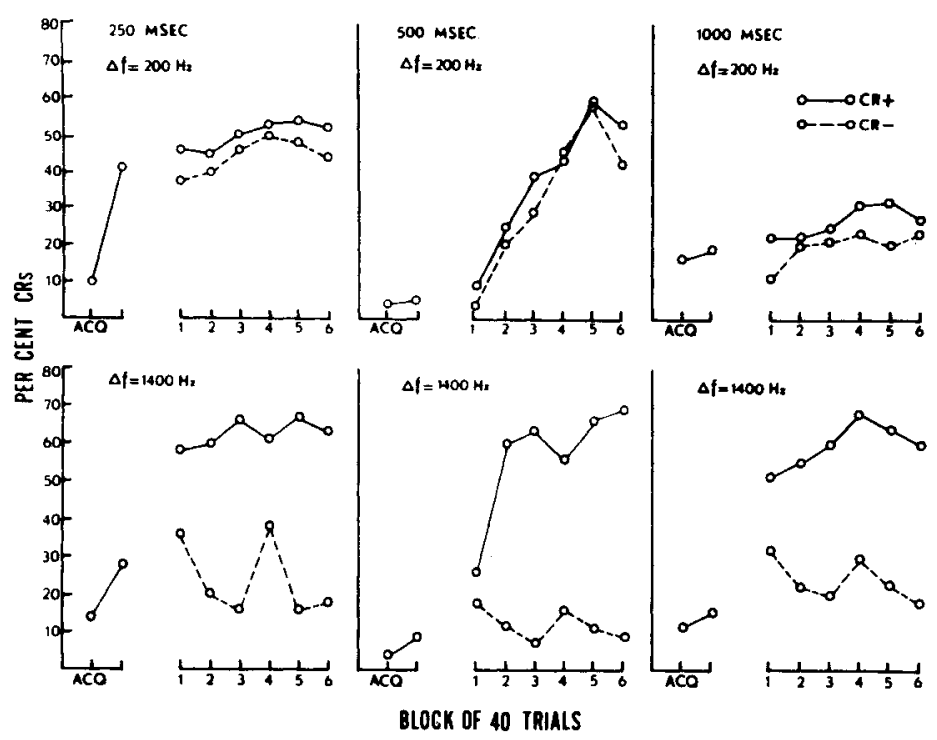

Fig. 1. Differential conditioning as a function of CS-UCS interval and tonal separation 
differentiation might have occurred under this condition is suggested by the outcome of a sign test on \%CR+ vs \%CR- for Day 3. Pooling over levels of ISI, 17 of the 24 Ss at $\Delta \mathrm{f}=200$ gave more $\mathrm{CRs}$ to $\mathrm{CS}+$ than to $\mathrm{CS}$ $(\mathrm{p}=.032)$. The difference in mean percentage of CRs to CS+ and CS- under the two $\Delta f$ conditions was significant $(F=39.66$, df $=1 / 36, p<.001$ ).

\section{EXPERIMENT $2^{3}$}

As expected from conditioningextinction theories of discrimination learning, the percentage of CRs to CSt and CSat $\Delta \mathrm{f}=200$ in Experiment 1 tended to fall between those observed at $\Delta f=1400$. This attenuation of performance under high cue similarity presumably arose from the suppressive influence of generalized inhibition from CS-, on the one hand, and the elevating influence of generalized excitation from CSt on $\mathrm{CR}-$, on the other. But the inhibitory influence, as reflected in the lower level of responding to $\mathrm{CS}+$ at $\Delta \mathrm{f}=200$ compared with $\Delta f=1400$, seemed too great in light of data from laboratories indicating a high level of conditioning under 50\% reinforcement (Coleman \& Gormezano, 1966). Since the inhibitory influence of nonreinforcement is theoretically greatest with complete CS overlap, we were concerned that a $50 \%$ partial reinforcement group, receiving the same sequence of reinforcement and nonreinforced trials, might not yield conditioning curves which fall somewhere between those obtained with discriminably different CSs, as is the case with human Ss (e.g., Gynther, 1957). Experiment 2 attempted to determine where the conditioning curves of a partial reinforcement group (complete CS overlap) fall in relation to groups receiving differential conditioning with discriminably different CSs.

\section{Subjects}

The Ss were 24 naive male and female New Zealand White rabbits, $90-120$ days old.

\section{Apparatus}

The apparatus was the same as in Experiment 1 .

\section{Procedure}

Two groups of eight rabbits each received differential conditioning with $\Delta f(\mathrm{~Hz})$ separations between $\mathrm{CS}+$ and $\mathrm{CS}-$ of 600 or $1200 \mathrm{~Hz}$. For $\Delta \mathrm{f}=600$ the two CSs were 400 and $1000 \mathrm{~Hz}$, and for $\Delta f=1200$ the two CSs were 400 and $1600 \mathrm{~Hz}$. In each case, the higher tone was CS+ for half the Ss. Partially reinforced Ss received one CS of either 400 or $1600 \mathrm{~Hz}$ for a total of eight animals. All groups were given 120 trials per day for 5 days using a conventional mixed-phase schedule of trials. The average intertrial interval was $50 \mathrm{sec}$, and the ISI was $250 \mathrm{msec}$. All other methodological details were the same as in Experiment 1.

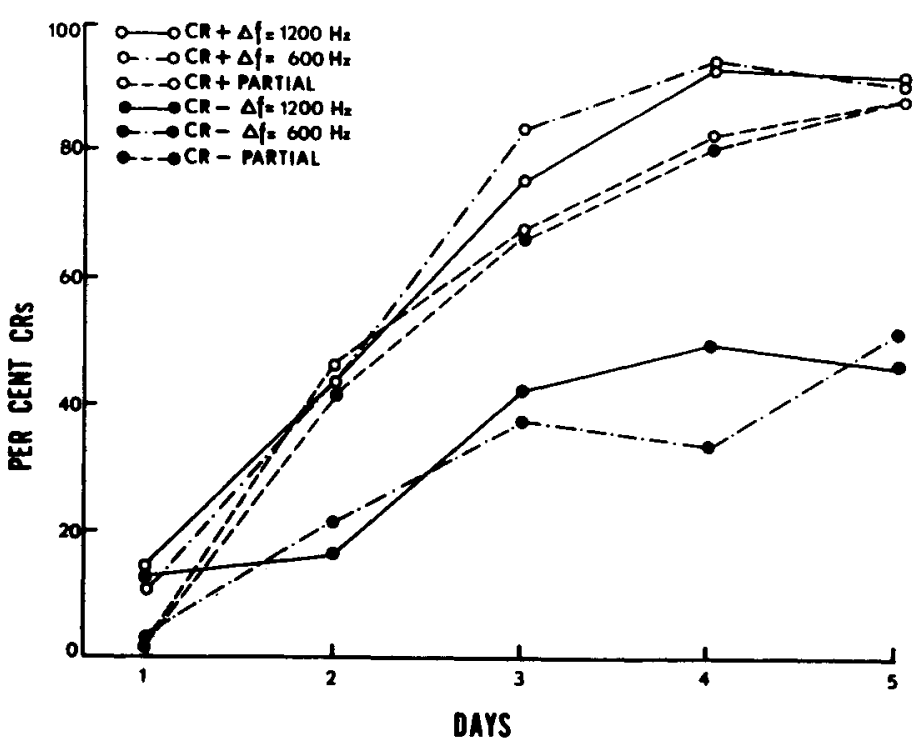

Fig. 2. Differential conditioning compared with $50 \%$ random reinforcement.

Results and Discussion

Figure 2 shows the CR+ and CR- curves ${ }^{2}$ as a function of days for each of the three main groups. Mean percentage of CRs of the partial reinforcement group was plotted separately for reinforced trials $(C R+$ partial) and nonreinforced trials (CR-partial). The partially reinforced group did fall between the curves for the two differential groups, but the mean percentage of CRs for the partial group did not differ significantly from the level of responding to CSt of the two differential groups. Moreover, the partial group did not reach asymptote until possibly the fifth day and would have undoubtedly matched the differential groups with further training. Whether this is a failure of the theory or an artifact of the $100 \%$ performance ceiling is unclear. Nevertheless, the sort of sustained asymptotic suppression under partial reinforcement which we expect in human eyelid conditioning (cf. Gynther, 1957; Moore, 1964) does not seem to occur with rabbits. It would therefore seem most parsimonious to attribute the unusually low levels of responding to CSt in the $\Delta \mathrm{f}=200$ groups of Experiment 1 to sampling error or the result of too few trials. This seems especially plausible in light of the relatively good differentiation and high level of responding to CS+ with rabbits reported by Frey \& Misfeldt (1967) using tones of 600 and $800 \mathrm{~Hz}$. Nevertheless, it would be premature to rule out altogether the possibility of a discontinuity in the relationship between level of responding to CS+ and the similarity between CSt and CS- such that a high degree of similarity lowers responding to CS+ but complete CS overlap, i.e., $50 \%$ partial reinforcement, does not.

\section{REFERENCES}

COLEMAN, S., \& GORMEZANO, I. Resistance to extinction of the conditioned nictitating membrane response: Effect of amount of acquisition training, and amount of asy mptotic overtraining. Psychonomic Society, St. Louis, 1966.

FREY, P. W., \& MISFELDT, T. J. Differential rabbit ey elid conditioning: Effect of magnesium pemoline. Psychonomic Science, 1967, 9, 425-426.

GYNTHER, M.D. Differen tial eyelid conditioning as a function of stimulus similarity and strength of response to the CS. Joumal of Experimental Psychology, 1957, 53, 408-417.

HARTMAN, T. F., \& GRANT, D. A. Differential eyelid conditioning as a function of the CS-UCS interval. Journal of Experimental Psychology, 1962, 64, 131-136.

MOORE, J. W. Differential ey elid conditioning as a function of the frequency and intensity of auditory CSs. Journal of Experimental Psychology, 1964, 68, 250-259.

O'MAL LEY, P., HUPKA, R. B., \& MOORE, J. W. Auditory differential conditioning of the rabbit nictitating membrane response: I. Effects of mixed- and separate-phase training. Psychonomic Science, 1969, 15, 123-124.

SCHNEIDERMAN, N., \& GORMEZANO, I. Conditioning of the nictitating membrane of the rabbit as a function of CS-US interval. Journal of Comparative \& Physiological Psychology, 1964, 57, 188-195.

VANDERCAR, D. H., \& SCHNEIDERMAN, $N$. Interstimulus interval functions in different response systems during classical discrimination conditioning of rabbits. Psychonomic Science, $1967,9,9-10$.

\section{NOTES}

1. This research was supported by NSF Grant GB 5480 .

2. The notations $\mathrm{CR}+$ and $\mathrm{CR}$ - are abbreviations for CRs to CS+ and CRs to CS-

3. The authors extend their sincere appreciation to Barry Glasgow for conducting this experiment. 